\title{
$\mathrm{CrW}$ 전율고용체 첨가 내열 알루미늄 합금에 관한 연구
}

\author{
김진평 ****• 성시영** 한범석 * • 김상호 ** \\ *자동차부품연구원, **한국기술교육대학교
}

\section{The Study of Heat Resistant Aluminum Alloy with CrW Homogeneous Solid Solution}

\author{
Jin-Pyeong Kim***†, Si-Young Sung*, Beom-Suck Han* and Sang-Ho Kim** \\ *Metal Materials \& Processing Engineering Center, Korea Automotive Technology Institute \\ **School of Energy · Materials · Chemical Engineering, Korea University of Technology and Education
}

\begin{abstract}
Recently, heat-resistant aluminum alloy has been re-focused as a downsizing materials for the internal combustion engines. Heatresistant Al alloy development and many researches are still ongoing for the purpose of improving thermal stability, high-temperature mechanical strength and fatigue properties. The conventional principle of heat-resistant $\mathrm{Al}$ alloy is the precipitation of intermetallic compounds by adding a variety of elements is generally used to improve the mechanical properties of $\mathrm{Al}$ alloys. Heat resistant aluminum alloys have been produced by $\mathrm{CrW}$ homogeneous solid solution to overcome the limit of conventional heat resistant aluminum alloy. From EPMA, it is found that CrW homogeneous soild solution phases with the size of 50-100 $\mu \mathrm{m}$ have been dispersed uniformly, and there is no reaction between aluminum and $\mathrm{CrW}$ alloy. In addition, after maintaining at high temperature of $573 \mathrm{~K}$, there is no growth of hardening phase, nor desolved, but CrW still exists as a homogeneous solid solution.
\end{abstract}

Key words: Heat resisting aluminium alloy, Homogeneous solid solution, Solid solution strengthening, Dispersion strengthening, Casting Al alloy

\section{1. 서 론}

알루미늄 합금은 건축용 구조재에서 부터 자동차, 전기전자, IT 및 스포츠 레져 분야까지 지속적으로 사용량이 증가하고 있 으며, 특히 자동차 분야에서는 환경 및 연비 규제가 종전의 권고에서 강제이행으로 변경되어 감에 따라서 자동차 선진국 및 선진메이커를 중심으로 적용이 증가하고 있다[1,2]. 한편, 갈수록 경쟁이 치열한 자동차 산업에서는 단순한 경량화만이 아니라 기존의 내연기관의 열효율 한계를 극복하고, 출력과 연 비를 모두 상승시키고, 또한 내연기관의 작동 온도를 올리면서 크기를 줄이는 다운사이징이 반드시 필요하다. 현재까지 개발된 내열 알루미늄 합금의 경우 고온에서 일정한 특성을 유지하기 위하여, 초기에는 과공정 $\mathrm{Al}-\mathrm{Si}[3]$ 합금에서 출발하여, $\mathrm{Al}-\mathrm{Si}-$
$\mathrm{Cu}[4]$ 합금에서는 $\mathrm{Al}-\mathrm{Cu}$ 사이의 금속간화합물을 이용한 합금 이 개발되었으며 일본의 도요타에 의해서 Al-Si-Cu-Mg-Ti-Fe$\mathrm{Sb}$ 합금까지 개발되었다. 도요타의 $\mathrm{Al}-\mathrm{Si}-\mathrm{Cu}-\mathrm{Mg}-\mathrm{Ti}-\mathrm{Fe}-\mathrm{Sb}$ 합 금은 단순한 합금 조성을 제어한 합금이 아니라, $\mathrm{Ti}$ 와 $\mathrm{Sb}$ 를 이용하여 2차 SDAS (Secondary Dendrite Arm Spacing)를 $40 \mu \mathrm{m}$ 이하로 제어하며, 열처리를 통하여 최적의 내열 특성을 발휘하도록 개발되었으며, 러시아의 VIAM 에서는 최근에 $\mathrm{VAL} 10$ 및 VAL 12 종의 합금 보다 내열 특성이 우수한 $\mathrm{Al}-\mathrm{Cu}-\mathrm{Mg}-\mathrm{Ag}$ 계 합금을 개발하였다. 그러나 현재까지 개발된 내열 알루미늄 합금은 대부분 알루미늄 기지에 금속간화합물을 정출 및 석출로 제어하는 방식이기 때문에, 내연기관의 부품과 같이 장시간 고온에서 유지되는 것이 반복되는 경우에는 강화 상으로 존재하고 있는 금속간화합물이 열역학적으로 평형을 유
Received: April 22, 2013 ; Accepted: June 24, 2013

Corresponding author: Jin-Pyeong Kim (KATECH)

Tel: +82-41-559-3336, Fax: +82-41-559-3288

E-mail: jpkim@katech.re.kr
Journal of Korea Foundry Society

2013. Vol. 33 No. 3, pp. 122 126

http://dx.doi.org/10.7777/jkfs.2013.33.3.122

ISSN 1598-706X

(C) Korea Foundry Society, All rights reserved.

This is an Open-Access article distributed under the terms of the Creative Commons Attribution Non-Commercial License (http://creativecommons.org/licenses/by-nc/3.0) which permits unrestricted non-commercial use, distribution, and reproduction in any medium, provided the original work is properly cited. 
지하기 위하여 기지금속인 알루미늄과 반응하여 새로운 중간상 을 형성하거나, 금속간화합물이 결정립 조대화 또는 분해가 일 어나 내열 특성이 저하되는 문제점을 가지고 있다. 본 연구에 서는 기존의 내열 알루미늄 합금과는 다르게 알루미늄과 고용 한이 없으면서, 알루미늄 융점 이상에서 서로 전율고용체를[5] 형성하는 2 원 합금을 첨가하여, 고온에서도 기지금속인 알루 미늄과 서로 반응하지 않고 안정한 합금의 가능성을 확인하고 자 하였다.

\section{2. 실험 방법}

\section{$2.1 \mathrm{Cr}-\mathrm{W}$ 전율고용체 합금 제조}

본 연구에서는 전율고용체를 형성하는 2 원계 합금 중에서 알루미늄과 고용한 없는 $\mathrm{Cr}$ 과 $\mathrm{W}$ 을 전율고용체 형태로 제조 하였다. $\mathrm{Cr}$ 및 $\mathrm{W}$ 의 융점이 각각 $2,179 \mathrm{~K}$ 와 $3,694 \mathrm{~K}$ 으로 일반적인 대기중의 전기로에서 합금화가 불가능하기 때문에 Fig. 1(a) 에 나타낸 Plasma Arc Melting(PAM) 방법으로 합 금화를 하였으며, PAM 장치를 (b) 에 나타내었다. $\mathrm{CrW}$ 의 제조는 $\mathrm{wt} \%$ 비율로 $50: 50$ 으로 각각 $250 \mathrm{~g}$ 씩 $99 \%$ 이상 의 순도 소재로 준비되었으며, $5,000 \mathrm{~K}$ 이상의 고온 플라즈마 아크로 용융하였다. 고온 플라즈마의 아크 열로 인한 $\mathrm{Cr}$ 의 휘 발을 최소한으로 줄이기 위하여, Granular 형태로 수냉동 도가 니의 하단에 $\mathrm{Cr}$ 이 장입되고, 그 위에 $\mathrm{W}$ 을 장입하는 순서로 1 차 용융시에는 $\mathrm{W}$ 의 용융열로 $\mathrm{Cr}$ 을 용융 시키는 방법을 적용하였다. $\mathrm{Cr}$ 과 $\mathrm{W}$ 이 장입된 후에는 $\mathrm{PAM}$ 의 챔버를 진 공펌프를 이용하여 $1.33 \times 10^{-1} \mathrm{~Pa}$ 까지 배기 후, $\mathrm{Ar}$ 가스를 $1.5 \times 10^{5} \mathrm{~Pa}$ 로 가압한 상태에서 버튼의 형태로 1 차 합금화
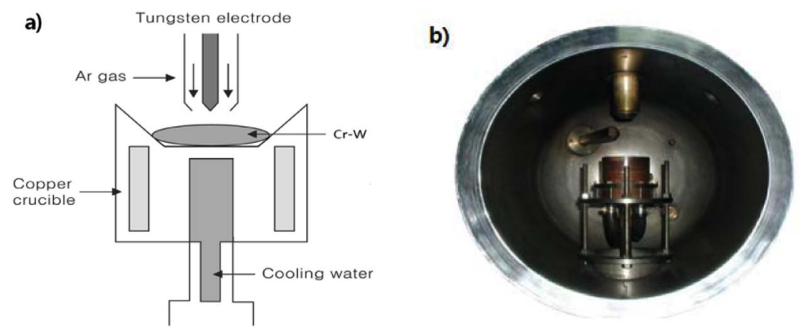

Fig. 1. Photograph of a Processing and Production method of CrW; (a) Plasma Arc Melting (PAM), (b) Vacuum induction melting furnace.
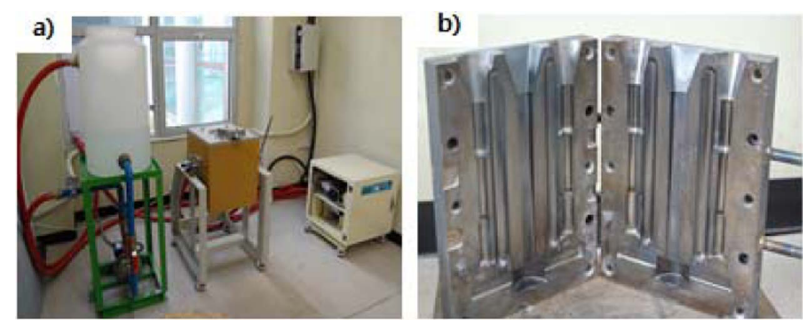

Fig. 2. Experimental facilities; (a) Induction Heating System, (b) The mold of specimens.
하였다. PAM 을 이용한 합금화 과정에서 $\mathrm{Cr}$ 의 휘발 손실을 최소화 하기 위하여 $\mathrm{Ar}$ 가스 가압 및 적층 순서에 의한 방법 으로 $\mathrm{Cr}$ 의 손실이 $0.1 \%$ 미만으로 미미하였으며, 충분한 합금 화 위하여 PAM 과정을 총 5 회 반복하여 재용융으로 합금화 하였다.

\subsection{Al-3 wt\% CrW 전율고용체 내열 알루미늄 합금 제조}

본 연구에서는 PAM 의 방법으로 합성된 크롬-텅스텐 $(\mathrm{CrW})$ 의 모합금을 첨가하여 전율고용체 내열 알루미늄 합금을 제조 하였다. $\mathrm{CrW}$ 전율고용체 모합금의 첨가 함량에 따른 합 금화 및 내열 특성을 평가하기 위하여, 모합금을 $3 \mathrm{wt} \% \mathrm{CrW}$ 의 조성으로 전율고용체 내열 알루미늄 합금을 제조하였다. Al$3 \mathrm{wt} \% \mathrm{CrW}$ 합금은 $\mathrm{CrW}$ 의 융점이 $2,000 \mathrm{~K}$ 이상이기 때문 에 일반적인 전기로가 아닌 Fig. 2(a) 와 같은 $20 \mathrm{kHz}, 20$ $\mathrm{kW}$ 급의 직접 유도 용융로를 이용하여 주조하였다. Al-3 $\mathrm{wt} \% \mathrm{CrW}$ 합금의 용융 및 주조 응고 과정에서 발생하는 결 함을 최소한으로 줄이기 위하여, 유도융용에 사용된 알루미나 계열의 클레이 도가니를 $1,173 \mathrm{~K}$ 에서 2 시간 이상 예열하여 수분을 완전히 제거 하였으며, $6 \mathrm{~kg}$ 정도의 순알루미늄을 $673 \mathrm{~K}$ 으로 예열한 후 용융을 하였다. 직접 유도용융을 통하여 용융된 알루미늄 용탕은 $953 \mathrm{~K}$ 도달 한 후, $523 \mathrm{~K}$ 으로 예열 된 $3 \mathrm{wt} \% \mathrm{CrW}$ 전율고용체 모합금을 투입하였으며, 첨가된 모 합금이 완전히 용융된 것을 확인한 후 용탕의 온도를 $993 \mathrm{~K}$ 에서 1분정도 유지하고, (b) 에 나타낸 ASTM B 108 규격의 금형에 주조를 하였으며, 주조결함을 줄이기 위하여 금형의 내 부를 $523 \mathrm{~K}$ 로 예열하였다. 제조된 $3 \mathrm{wt} \% \mathrm{CrW}$ 전율고용체 내열 알루미늄 합금의 미세조직 관찰을 위하여, 주조 합금을 금형에서 분리하여 $20 \mathrm{~mm}$ 정도 절단된 시편을 미세연마 후 $98 \%$ 증류수에 $2 \%$ 불산 $(\mathrm{HF})$ 희석용액을 이용하여 에칭 후 광 학현미경을 사용하여 분석하였으며, 첨가된 전율고용상의 상분 석을 위하여 EPMA (Electrone probe X-ray microanalyzer) 및 XRD (X-ray Diffraction) 를 이용하였다.

\section{3. 결과 및 고찰}

\section{$3.1 \mathrm{Al}-3 \mathrm{wt} \% \mathrm{CrW}$ 전율고용체 내열 알루미늄 합금의 미세조직 관찰 및 상분석}

본 연구에서 제안하는 전율고용체 내열 알루미늄 합금의 고 온강화기구는 Fig. 3 에 나타낸 바와 같이 $\mathrm{M}$ 과 $\mathrm{N}$ 의 합금

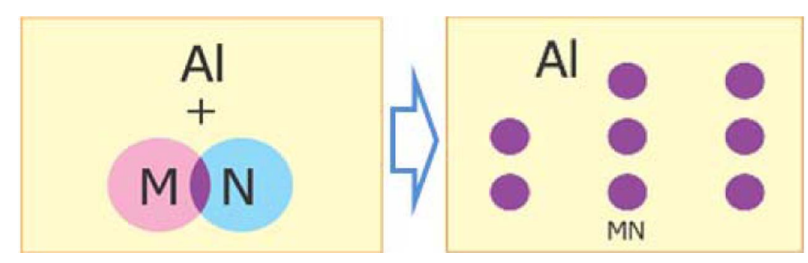

Fig. 3. The condition of heat resisting aluminium alloys. 
a)

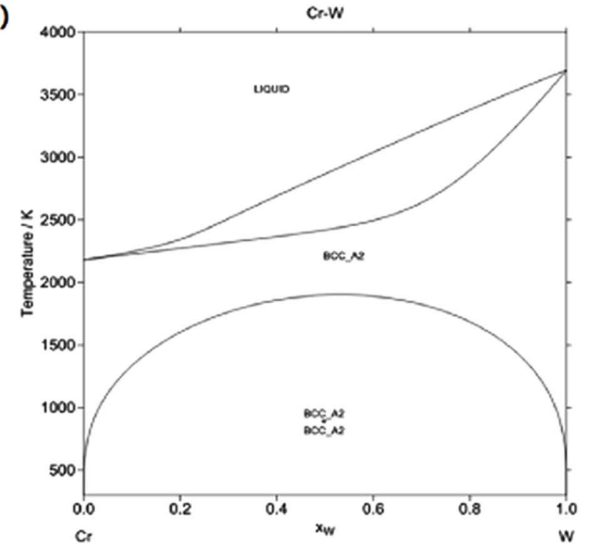

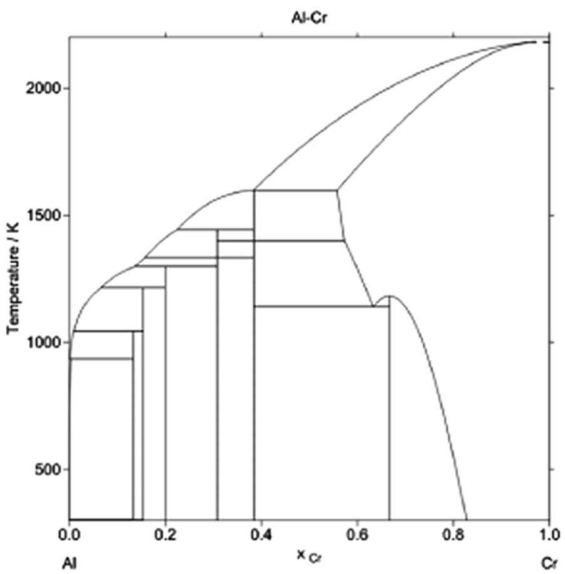

c)

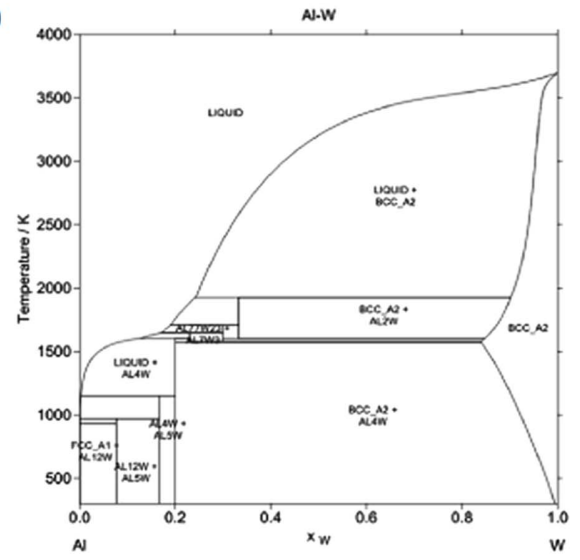

Fig. 4. Design of homogeneous solid solution alloys Al-CrW; (a) Two phase of alloy CrW, (b) Phase of alloy Al-Cr, (c) Phase of alloy Al-W.

원소를 단일상으로 제조하여 알루미늄 기지에 분산제어하는 방 법으로 고온에서도 단일 상으로 안정한 전율고용체를 형성하면 서 알루미늄 기지와는 반응하지 않는 2 원계의 첨가 내열 알 루미늄 합금이다.

본 연구에서 주목한 전율고용체 내열 알루미늄 합금의 조성 은 $\mathrm{Cr}-\mathrm{W}$ 의 2 원계 전율고용체를 선정하였다. 그 이유는 $\mathrm{Cr}-$

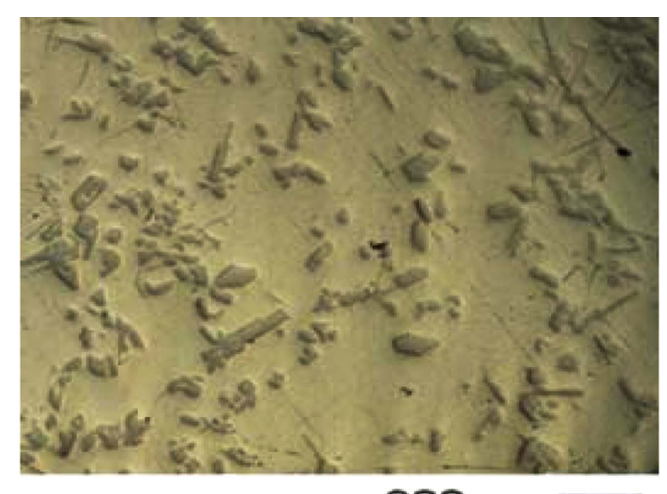

$200 \mu \mathrm{m}$

Fig. 5. Microstructure of homogeneous solid solution alloys Al-3 wt $\% \mathrm{CrW}$.
$\mathrm{W}$ 전율고용체는 Fig. 4(a) 의 Cr-W 2 원계의 상태도에서 확 인할 수 있듯이 전율고용의 단상으로 융점이 $2,000 \mathrm{~K}$ 이상으 로 높기 때문에, 전율고용체를 형성한 후에는 고온까지 안정한 단일 상을 유지할 수 있는 것을 확인할 수 있었으며, 알루미 늄 용탕과의 반응성에 있어서는 (b) 에 나타낸 Al-Cr 및 (c) 에 나타낸 Al-W 의 2 원계 상태도에서 확인할 수 있듯이 알 루미늄과 금속간화합물을 형성하지만 알루미늄에 고용한이 거의 존재하지 않기 때문에, $\mathrm{Cr}-\mathrm{W}$ 을 전율고용체로 합성하여 알루 미늄 기지에 첨가할 경우 $\mathrm{AlCr}$ 및 $\mathrm{AlW}$ 계열의 금속간화합물 의 상으로 분해가 어려울 것으로 예측되었기 때문이다.

Fig. 5 는 $\mathrm{Al}-3 \mathrm{wt} \% \mathrm{CrW}$ 내열 알루미늄 합금의 미세조직 을 나타내었다. 기지금속인 알루미늄 합금에 Facet 형태의 상 들이 관찰되었으며, 크기는 약 $50 \sim 150 \mu \mathrm{m}$ 로 복합재료의 강 화상과 같이 기지인 알루미늄과는 다른 것을 확인할 수 있었 다. Facet 형태의 상의 종류는 미세조직 상에서는 단일상으로 판단된다. 그러나, Fig. 5 의 미세조직에서 확인된 Facet 형태 의 상이 전율고용체를 형성하고 있는 $\mathrm{CrW}$ 의 단일 조성으로 이루어져 있는 것인지를 확인하기 위하여 EPMA 분석을 하였 다. EPMA 분석 결과는 Fig. 6 에 나타냈으며, 각진 Facet 형태의 상에서 $\mathrm{Cr}$ 과 $\mathrm{W}$ 이 균일한 농도로 분포되고 있으며, 

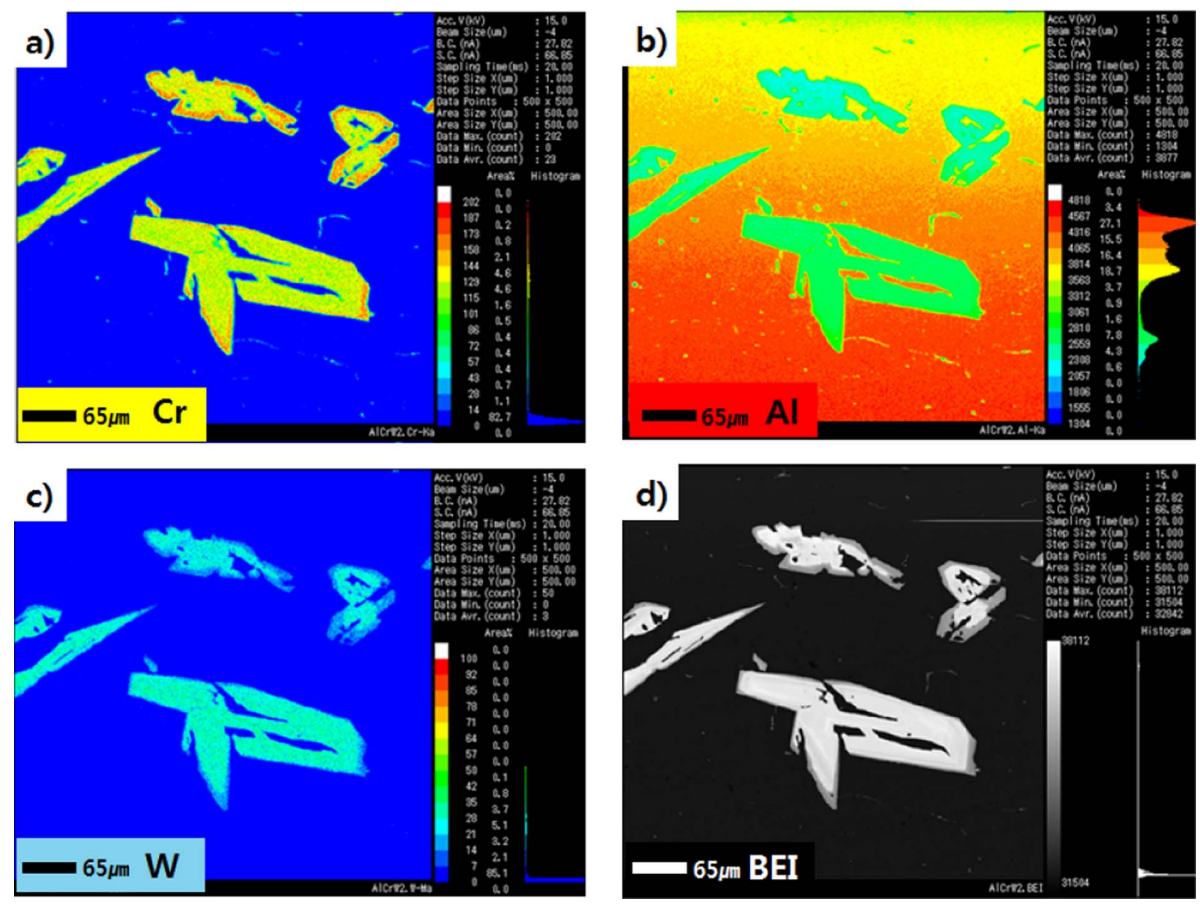

Fig. 6. EPMA of homogeneous solid solution alloys Al- 3 wt\% CrW; (a) Phase Cr, (b) Phase Al, (c) Phase W, (d) BEI.

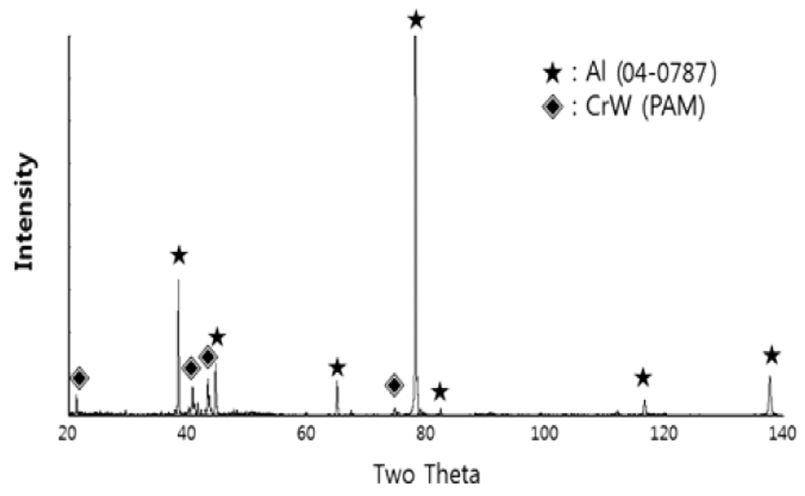

Fig. 7. XRD analysis result of casting Al-3 wt\% CrW alloys.

동일한 부위에서 $\mathrm{Al}$ 의 농도는 현저하게 낮아지는 것을 확인 하였다. 이러한 결과를 토대로 $\mathrm{Cr}$ 과 $\mathrm{W}$ 합금을 전율고용체로 합금화하여 첨가하였을 때 단일상으로 존재할 가능성이 높은 것으로 판단되었다.

본 연구에서는 $\mathrm{Al}-3 \mathrm{wt} \% \mathrm{CrW}$ 내열 알루미늄 합금의 Facet 형태의 상을 $\mathrm{CrW}$ 전율고용체 단일상 임을 명확히 하고자 $\mathrm{XRD}$ 상분석을 실시하여 관찰하였다. $\mathrm{XRD}$ 에 의한 상분석을 진행하기 위하여, JCPDS 카드 상에서 $\mathrm{Al}, \mathrm{Cr}$ 및 $\mathrm{W} 3$ 원계의 조성으로 형성될 수 있는 상들인 $\mathrm{Al}, \mathrm{Cr}, \mathrm{W}, \mathrm{AlCr}_{2}, \mathrm{Al}_{8} \mathrm{Cr}_{5}$, $\mathrm{Al}_{4} \mathrm{~W}, \mathrm{Al}_{12} \mathrm{~W}$ 에 대한 결정학적 데이터를 확인할 수 있었지만, $\mathrm{CrW}$ 전율고용체의 경우에는 $\mathrm{XRD}$ 분석을 위한 데이터가 존재 하지 않기 때문에, $50: 50 \mathrm{wt} \%$ 비율로 $\mathrm{CrW}$ 모합금을 제조하 여 비교 평가하였다. XRD 분석 조건을 $20^{\circ}$ 에서 $140^{\circ}$ 의 각도 a)

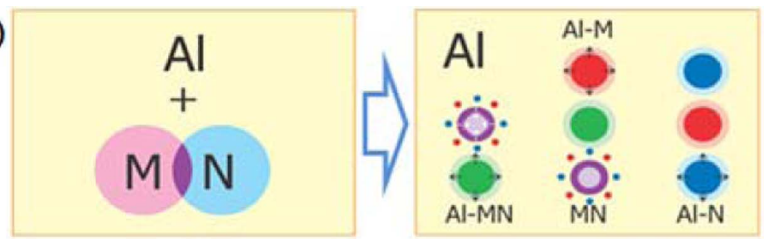

b) TMERMOCCALC ACBA

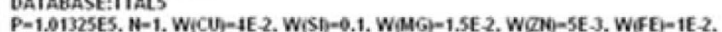

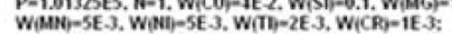

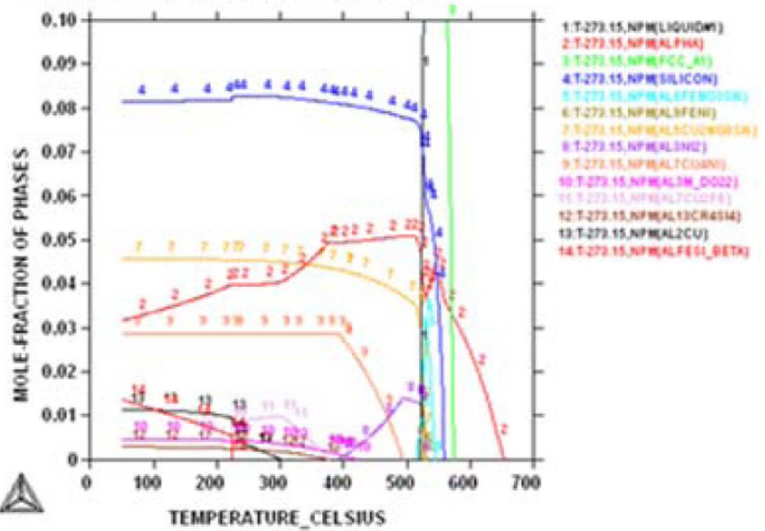

Fig. 8. The conventional of heat resistant aluminium alloy ; (a) Effects of heat resistant aluminium alloys and (b) Simulation of temperature phase AC8A.

를 분당 $2^{\circ}$ 간격으로 Scan 분석 하였다. XRD 분석의 결정학 적 데이터를 활용하여 Fig. 7 의 결과에서 확인할 수 있듯이 순수한 알루미늄과 $\mathrm{CrW}$ 전율고용체로 이루어진 합금임을 확인 

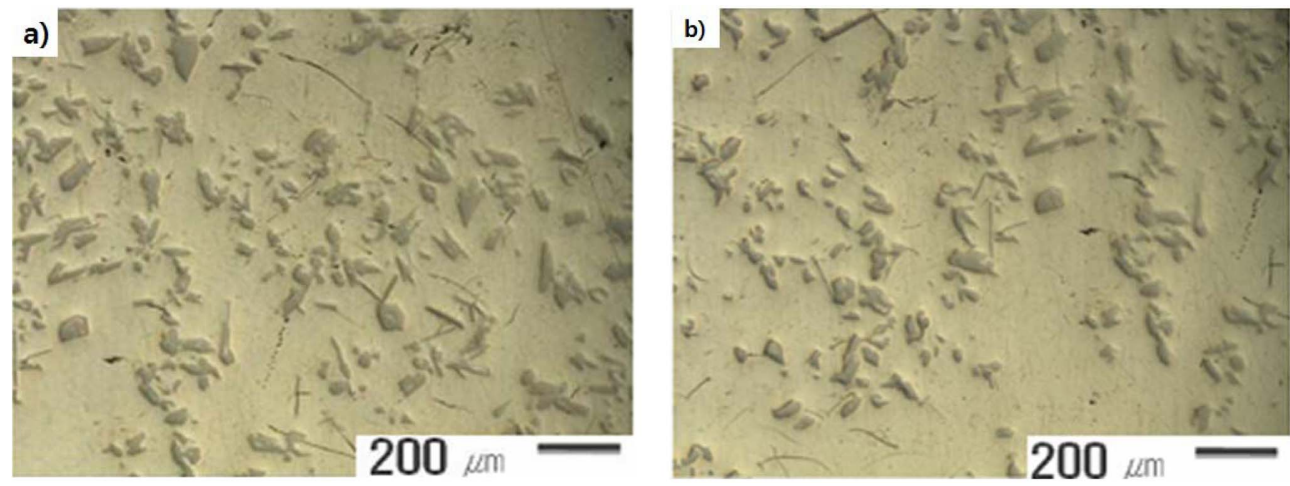

Fig. 9. Typical microstructure of Al-3 wt\% CrW alloys; (a) Heat treated specimen with $573 \mathrm{~K}, 200 / \mathrm{h}$ (b) Remelting specimen.

할 수 있었다. 따라서 EPMA 와 XRD 분석을 바탕으로 알루 미늄 기지금속에 $\mathrm{CrW}$ 전율고용체만으로 이루어진 합금의 제조 가 가능한 것을 확인할 수 있었다.

\section{$3.2 \mathrm{Al}-3 \mathrm{wt} \% \mathrm{CrW}$ 전율고용체 내열 알루미늄 합금의 고온 거동}

기존의 내열 알루미늄 합금은 Fig. 8(a) 에 나타낸 것과 같 은 방법으로 알루미늄 기지 금속에 $\mathrm{M}$ 과 $\mathrm{N}$ 의 합금 원소를 첨가하여, 응고와 열처리를 통하여 미세한 석출물의 형태로 분 산제어하여 내열 특성을 나타내었다. 그러나, 내열합금이 고온 에서 지속적으로 유지될 경우 열역학적으로 평형을 이루기 위 하여 $\mathrm{M}$ 과 $\mathrm{N}$ 함금이 각종 반응을 일으켜서 결정립 조대화 및 분해가 일어나는 현상이 있다. 이러한 열역학적 특성을 관 찰하기 위하여 (b) 에 나타낸 Thermo-calc 상분석 프로그램을 이용하여 현재 피스톤 소재로 사용되고 있는 $\mathrm{AC} 8 \mathrm{~A}$ 소재에 대하여 상분석을 실시하였다. 열역학적 상분율 변화에 대한 계 산으로 확인된 바와 같이, $523 \mathrm{~K}$ 이하에서 다양한 상들의 분 율 변화를 확인할 수 있으며, 특히 $373 \mathrm{~K}$ 에서 $523 \mathrm{~K}$ 의 구간 에서 상들의 분율 변화가 심하기 때문에 상용합금의 경우 내 열 한계 온도를 $373 \mathrm{~K}$ 정도로 제한을 두고 있다.

$\mathrm{Al}-3 \mathrm{wt} \% \mathrm{CrW}$ 내열 알루미늄 합금이 기존의 내열 알루미 늄과 달리 고온에서 전율고용체가 안정한 상으로 존재하는지를 확인하기 위하여, 기존 내열 알루미늄 합금의 내열 한계인 $423 \mathrm{~K}$ 보다 $150 \mathrm{~K}$ 이상 높은 $573 \mathrm{~K}$ 에서 200 시간을 유지한 후에 미세조직을 관찰하였다. Fig. 9(a) 관찰 결과 Fig. 5 의 열처리 이전 주조시편과 차이가 없었으며, (b) 는 $\mathrm{Al}-3 \mathrm{wt} \%$ $\mathrm{CrW}$ 조성의 내열 알루미늄 합금을 재용융 한 후에 미세조직 을 나타내었다. 1 차 주조한 시편과 2 차로 재용융 주조 시편에 서 $\mathrm{CrW}$ 상들의 변화가 없이 동일한 것을 확인할 수 있었다.
$\mathrm{Al}-3 \mathrm{wt} \% \mathrm{CrW}$ 내열 알루미늄 합금에 첨가한 $\mathrm{CrW}$ 전율고용 체의 경우 융점이 알루미늄 합금보다 $1,200 \mathrm{~K}$ 이상 높기 때문 에 재용융시에도 전율고용체의 변화가 없던 것으로 사료된다. 이러한 결과를 바탕으로 $\mathrm{Al}-3 \mathrm{wt} \% \mathrm{CrW}$ 의 전율고용체 내열 알루미늄 합금의 가능성을 확인을 하였다.

\section{4. 결 론}

본 연구에서는 전율고용체 첨가 내열 알루미늄 합금 제조를 수행한 결과 다음과 같은 결론을 얻을 수 있었다.

1) 전율고용체 내열 알루미늄 합금 제조 시 첨가 합금이 기 지 금속과 반응하여 불안정한 화합물을 형성하지 않음을 확인 하였다.

2) $573 \mathrm{~K}$ 이상의 고온에서 장시간 유지 시 첨가된 강화상이 분해되거나 결정립 조대화 되지 않음을 확인 할 수 있었다.

3) 전율고용체 내열 알루미늄 합금의 용융시 $\mathrm{Cr}$ 과 $\mathrm{W}$ 첨가 원소가 전율고용체 단일 상으로 존재하고 있음을 확인하였다.

\section{참고문헌}

[1] J. S. Park, S. Y. Sung, B. S. Han, C. H. Jung, K. A. Lee, Kor. J. Met. Mater. 48, 1, (2010).

[2] W. S. Miller, L. Zhuang, J. Bottema, A. J. Wittebrood, P. De Smet, A. Hazler, A. Viereagge, Mater. Sci. Eng. A 280 (2000).

[3] M. A Suarez, I. Figueroa, A. Cruz, A. Hernandez, J. F. Chavez, Mater. Res. 15 (2012).

[4] W. F. Smith, Structure and properties of engineering alloys, 2nd Ed. McGraw-Hill, 178-238.

[5] S. Y. Sung, B. S. Han, Heat resistant aluminum alloy, and method for manufacturing same, EN (2010). 